\title{
El intento estadunidense de apoderarse de Canadá durante la administración del presidente Polk, 1845-1849
}

Lawrence Douglas Taylor Hansen

DIPAR'TAMENTO DI ESTUDIOS DE NORTTAMERICA

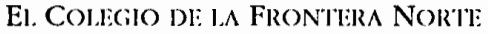

En este artículo se analiza el interés de los expansionistas

estadunidenses por apoderarse de toda la América del

Norte británica. Frente a la determinación del gobierno

británico para preservar Canadá como parte de su dominio colonial, el presidente Polk cedió en su empeño.

La desilusión de los expansionistas se desvaneció con

el estallido de la guerra contra México, que abrió camino para la extensión estadunidense hacia el sur.

$\mathrm{D}$ entro de la historiografia del continente norteamericano, se ha discutido la premisa del "Destino Manifiesto" frecuentemente, con referencia al caso de México, y en particular, a la guerra de 1846 1848 entre este país y Estados Unidos, la llamada "compra" de La Mesilla y las expediciones filibusteras de la década de 1850 , y así muchos otros acontecimientos relacionados con el proceso de la expansión territorial de Estados Unidos durante el siglo XIX. Cabe señalar, sin embargo, que el "Destino Manifiesto", en términos de objetivos y realización, también estaba dirigido hacia la porción septentrional del continente, es decir, en contra del territorio que hoy en día constituye ia nación de Canadá.

El presente trabajo no tiene como propósito el de analizar a fondo el proceso de negociación que dio como resultado la firma del tratado de 1846 y que dividió el territorio de Oregon entre Estados Unidos y Canadá, dado que este tema ha sido quizá el que ha recibido más atención por parte de los historiadores que han estudiado la historia de las relaciones entre estas dos naciones. Es más bien, un intento de situar este episodio dentro del con- 


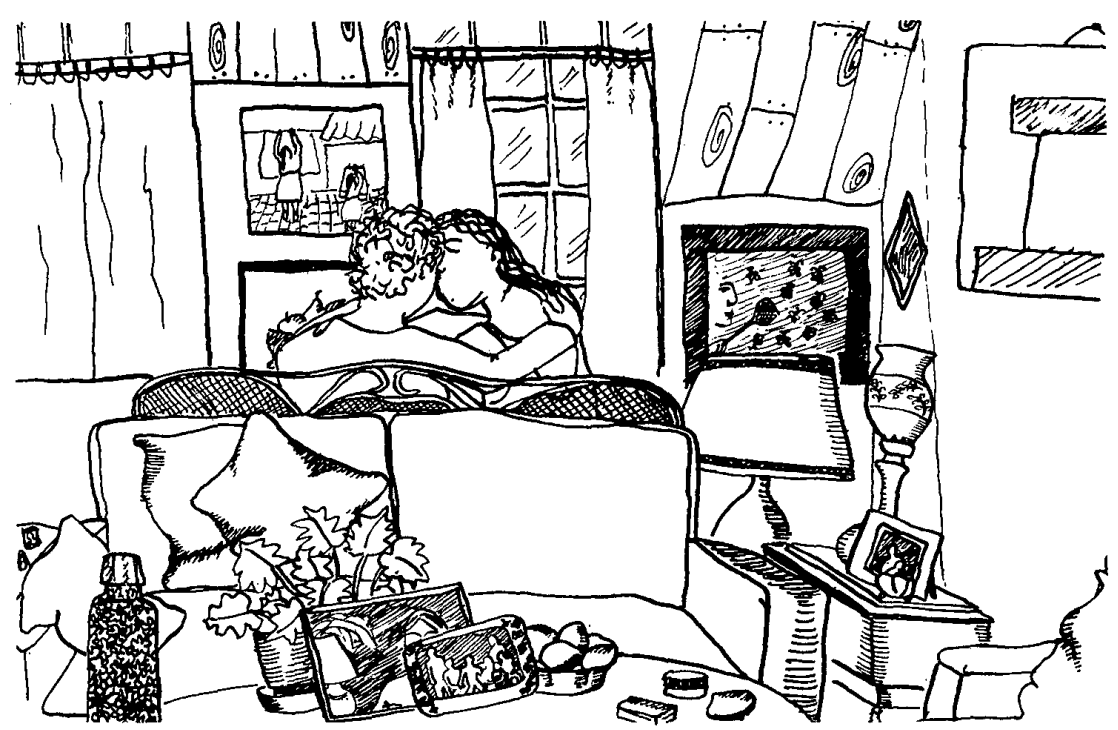

texto total del movimiento expansionista estadunidense del siglo XIX, que tuvo como objetivo, no sólo la adquisición de la región de Oregon, sino también el intento de apoderarse de toda la América del Norte británica.

El movimiento expansionista estadunidense hacia Canadá se remonta a la época de la guerra de Independencia, cuando las colonias rebeldes, en los años de 1775-1776, dirigieron una campaña contra esa provincia con el objetivo de conquistarla por la fuerza de las armas. ${ }^{1}$ Samuel Adams, uno de los más destacados jefes revolucionarios, decla-

1 Para descripciones detalladas de esta campaña, véase Smith, Our Struggle, 1907; Kerr, "American", 1936, pp. 433-444 y Mackay Hitsman, Safeguarding, 1968, pp. 21-45. ró en una carta al reverendo Samuel Cooper, cabecilla rebelde de Boston:

Nueva Escocia y Canadá podrían servir para proteger las pesquerías. La cesión de aquellos territorios eliminaría cualquier pretexto por parte de Gran Bretaña con el objetivo de perturbar nuestra paz en el futuro y acabaría con una fuente de influencia británica corrupta que, emanando de ellos, podría actuar como un veneno, provocando problemas en general a lo largo de los estados[...] $]$ No sería mejor para nosotros, si resulta factible, quitar estas regiones al enemigo por la fuerza en lugar de confiar en la inseguridad de los tratados:?

2 Samuel Adams al reverendo Samuel Cooper, 29 de abril 1779 , en Alonzo, Writings, 1908, vol. 4, pp. 149-150. 
A pesar del fracaso de la campaña para conquistar entonces Canadá, algunos estadunidenses nunca perdieron de vista esta meta. En una carta que Thomas Jefferson dirigió a James Madison en 1809, mencionaba, con referencia a la posible adquisición de la isla de Cuba por Estados Unidos en el futuro, que Canadá también podría ser incorporado finalmente a la Unión Americana. Durante un debate a principios de 1812, John R. Harper, diputado del estado de Nueva Hampshire, aseveró en la Cámara de Representantes: "Me parece que la intención del Autor de la Naturaleza es que el Golfo de México constituya el límite de nuestro territorio en el sur, y las regiones de las heladas eternas en el norte. ${ }^{3}$ Poco después, durante la guerra con Gran Bretaña de 1812 a 1814, los estadunidenses hicieron otro intento infructuoso para subyugar a $\mathrm{Ca}$ nadá por medio de la fuerza. ${ }^{4}$

La noción de "Destino Manifiesto" alcanzó su etapa de desarrollo completo durante la época jacksoniana, siendo su órgano de difusión la revista mensual The Democratic Review, fundada en 1837 por John L. O'Sullivan, inmigrante de origen irlandés. En una serie de articulos publicados en esta revista, Sullivan argumentaba que la política anexionista estadunidense era necesaria para evitar que otras naciones se apoderaran del continente.

3 Annals of the Congress of the United States, 120 . Congreso, $1^{2}$ Sesión, parte 1 (18111812), columna 657.

4 Pratt, Expansionists, 1957, pp. 17.59 y 153-188; Mackay Hitsman, Incredible, 1965, pp. 61-237, y Mackay Safeguarding, 1968, pp. 79-109.
No sólo deberían ser anexados los territorios de Texas y California, sino también aquellos gobernados por los británicos y manejados a través de empresas comerciales de esta nacionalidad, tales como la Compañia de la Bahía Hudson. "De hecho", O'Sullivan comentaba, "hay mucho anexionismo entre la generación actual, a lo largo de toda la frontera norte, aunque aún no se haya puesto en práctica." 5

Para muchos expansionistas estadunidenses de este periodo, Canadá era más atractivo como territorio potencial de adquisición que otras regiones del hemisferio, dado que consideraban un peligro, para la sociedad estadunidense, la incorporación de pueblos de diferentes orígenes raciales, religiosos y étnicos. De todos los pueblos de las Américas, los canadienses anglosajones eran semejantes a los estadunidenses en cuanto a los elementos básicos de carácter cultural y vida política. Este sentido de afinidad con tales canadienses se acrecentó, durante la década de 1840 , debido al agudizamiento del concepto de homogeneidad racial, o preferencia por la gente de ascendencia anglosajona frente a los mestizos de Hispanoamérica. A pesar de que un gran porcentaje de los habitantes de Canadá eran de origen colonial francés, los estadunidenses contemplaban el rápido incremento del sector anglo de la población debido a la creciente ola de

5 O'Sullivan, "Annexation", 1947, pp. 563568 (publicado antes en Democratic Review, 17 julio, 1845); Pratt, "John L. O'Sullivan", 1933, pp. 222-224 y Pratt, "Origin", 1927, pp. 795-798. 
inmigración proveniente de las Islas Británicas y de Estados Unidos. ${ }^{6}$

Algunos expansionistas opinaban que las poblaciones de las dos colonias británicas principales de Canadá -Alto Canadá y Bajo Canadá- estaban predispuestas a unirse con Estados Unidos voluntariamente. En febrero de 1844, Sidney Breese, un senador de Illinois, aseguró a sus compañeros del Senado que los canadienses simpatizaban con los ideales republicanos estadunidenses. En junio del mismo año, Levi Woodbury, durante otra discusión en el Senado, predijo que los dos Canadás podrían ser anexados pacíficamente. ${ }^{7}$ John O'Sullivan, en su papel de editor del New York Morning News, profetizó también que, después de la anexión de Texas, los canadienses no tardarían en "sentirse avergonzados de su estado de esclavitud, y, librándose de este yugo, se independizarían." ${ }^{8}$ Los canadienses ya ha-

6 Wcinbcrg, Manifesl, 1963 , pp. 355-364; Horsman, Race, 1981, pp. 130-131 y 208-227; Hictala, Manifest, 1985, pp. 132-172.

7 Relerente a los comentarios de Brecse, véasc cl Congressional Globe, 280. Congreso,

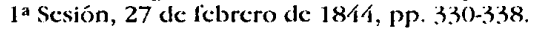
Relativo a la opinión expresada por Woodluury, véasc la misma liucntc, $\Lambda$ péndice ( 1 de junio de 1811), pp. 760-775.

${ }^{8}$ Neu, York Monning Neus, 14 de julio de 1845, citado en Merk, Manifest, 1963, p. 50. Para algunas opiniones semcjantes, véasce los comcntarios cditoriales del New York Ilerald, 30 de novicmbre de 1845, y del Neu York? Morring Neu's, 7 de julio de 1845, citados en la misma fucnte, p. 50; discurso de l.cwis C. Levin, diputado congresional de Pennsylvania, en Congressionat cilobe, 290. Congreso, $1^{\text {a }}$ Sesión, 9 de concro de 1816, spéndice, pp. 95-96; así como Adams, Pouer, 1969, pp. 7479. bían dado evidencias de su "carácter rebelde" durante las insurrecciones de 1837 en las regiones del Alto y del Bajo Canadá.

Sin embargo, la milicia canadiense también había combatido al lado de unidades de tropa regular británica en defensa de los ataques lanzados a sus poblaciones desde territorio estadunidense como consecuencia de estas mismas rebeliones. ${ }^{9}$ Era poco probable, entonces, que se efectuara una unión voluntaria entre Canadá y Estados Unidos en un futuro próximo. En consecuencia, a partir de 1840 , algunos expansionistas estadunidenses comenzaron a creer que la guerra podría ser la mejor opción para adquirir la anhelada región. ${ }^{10}$

Cuando James K. Polk asumió el cargo de presidente de Estados Unidos en marzo de 1845, existían dos zonas de conflicto internacional potenciales: la parte sur de Texas, en contra de México, y el territorio de Oregon ${ }^{11}$ en el noroeste, en contra de Gran Bretaña; de estos dos, los estadunidenses consideraban al último como el más peligroso. Para muchos estadunidenses, sobre todo para los que pertenecían al Partido Demócrata, Gran Bretaña, gobernada por una

9 Portcr: "Canadian", 1926, pp. 13-22; Morton, American, 1937, pp. 163-169; Mclnnis, Unguarded, 1912, pp. 152-155.

io Preston, Defense, 1977, p. 17.

11 lil árca conocida como Orcgon aharcaba los cestaclos modernos de Oregon, Washington, c Idaho, así como pequeñas porciones de Montanal y Woming que se ubicahan al ocsic de la vertiente continental de la Sicrrat Madere oceidental. También se extendra hacia al norte a un punto indeterminado al sur de Alaska. DeVoto, Year; 1943, p. 5. 
monarquía y centro del imperio más poderoso del mundo en aquel tiempo, parecía ser la personificación de la tiranía y de la agresión. Ya había sido el adversario de su país en dos guerras largas y sangrientas, cuya memoria todavía era fuente de un gran rencor entre ellos.

Desde el final del segundo de estos conflictos, el de 1812-1814, las relaciones entre Estados Unidos y Gran Bretaña no habían sido muy cordiales. El mismo duque de Wellington opinó que "lo más probable es que tendremos una guerra antes de poder arreglar nuestros problemas con Estados Unidos." El tratado de Webster-Ashburton de 1842, que estableció de manera más o menos definitiva las fronteras entre Maine y Nueva Brunswick, había sido concluido por una administración whig; los demócratas lo interpretaron como el triunfo de una reclamación británica fraudulenta, así como la pérdida de una porción de territorio -aquella parte cedida a la Nueva Brunswick-que debería pertenecer a Estados Unidos. ${ }^{12}$ Algunos estadunidenses consideraban que los británicos habían cercado a Estados Unidos por todos lados y que quedaba latente el peligro de un futuro ataque inglés, originado en cualquier punto de la inmensa extensión territorial del norte, desde los Grandes Lagos hasta la costa del Pacífico. También pensaban que California y Texas estaban en

12 Joncs y Vinson, "British", 1953, p. 354. para un cstudio detallado de los problemas en torno a las negociaciones para fijar los limitcs cntrc Canada y listados Unidos en el norestc, véasc H. Jones, Webster-Ashburlon, 1967. peligro de caer bajo el control inglés, y que existía una situación semejante con respecto a México, América Central y porciones del Caribe. ${ }^{13}$

De manera semejante, la presencia de los británicos en la región de Oregon y del noroeste del Pacífico era calificada en general, por muchos estadunidenses, como otro intento de colonización de América por una potencia imperial europea, misma que disputaría a su gobierno el derecho a aquellas regiones del norte que él reclamaba como suyas.

Por medio del Tratado de la Florida, firmado en 1819, Estados Unidos había adquirido un territorio reclamado por España, el cual se extendía a lo largo de la costa del Pacífico, desde el paralelo $42^{\circ}$, que marcaba el límite septentrional de la Alta California, hasta el $54^{\circ} 40^{\prime}$ que constituía la frontera sur del territorio ruso de Alaska. En 1824, se firmó un tratado entre Rusia y Estados Unidos reconociendo este último paralelo como el límite sur del imperio ruso en América del Norte. Al año siguiente, el gobierno británico firmó su propio tratado con los rusos en el que reconoció el mismo paralelo como frontera sur de Alaska, con algunas modificaciones. Especificó, por ejemplo, que la línea divisoria no debería extenderse más de diez leguas hacia el interior del continente desde el punto de la costa afectada por la marea y que, al norte del paralelo $59^{\circ}$, debería ser acotada por el meridiano $141^{\circ}$ en lugar del $139^{\circ}$.

13 Adams, Brilish, 1963, Pp. 226-26/; Mcrk, Monroe Doctrine, 1966 , pp. vil y ix; Jackson, "Probritish", 1973, pp. 105-140. 
Según una convención celebrada entre Estados Unidos y Gran Bretaña en 1818 , se acordó que la región fuera gobernada por un sistema de joint occupation, u ocupación por ambas naciones, aunque de hecho nunca existió ninguna forma de gobierno colateral o de condominio; más bien, los artículos del tratado concedieron a los ciudadanos de sus respectivos países el goce de derechos iguales relativos a la colonización y al comercio dentro del territorio situado entre la costa y la sierra. ${ }^{14}$ Entre tanto, y a lo largo del cuarto de siglo que siguió, los dos gobiernos propusieron sus propias soluciones para resolver el problema de la soberanía. El gobierno estadunidense propuso que la línea divisoria siguiera el paralelo $49^{\circ}$, el cual, según la convención de 1818 , formaba la porción de la frontera entre Canadá y Estados Unidos, ubicada entre el lago de los Bosques y el límite más al este de la cordillera de las montañas Rocallosas. ${ }^{15}$ Su contraparte británica opinaba, en cambio, que la frontera debería seguir este paralelo únicamente hasta el punto donde se intersectaba con el río Columbia, continuando de allí a lo largo del cauce principal del río hasta el océano. Ninguno de los dos gobiernos consideraba que el territorio en disputa, es decir, el situado al norte del río Columbia, fuera adecuado para la agricultura, ni pudiera ser fuente de otra forma de riqueza;

14 El texto del tratado, firmado el 20 de octubre de 1818, se encucntra en Miller, Treaties, 1931-1948, pp. 10-11.

is Paullin, "Early", 1923, p. 127; McInnis, Unguarded, 1942, pp. 171-173. no obstante, ambos querían útilizarlo como instrumento en la mesa de negociación para obligar a su oponente a reconocer sus respectivos "derechos" sobre alguna parte de la zona. ${ }^{16}$ Debido a que no se logró llegar a un acuerdo en lo referente a establecer sus respectivos límites territoriales, el arreglo de ocupación conjunta fue continuado, por medio de otra convención celebrada en 1827 , y estableciendo que duraria hasta que cualquiera de los dos países optara por concluirla, con tal de que se diera un aviso previo de doce meses. ${ }^{17}$.

No obstante, la inmigración a Oregon de un creciente número de colonos procedente del este de Estados Unidos, durante los años iniciales de la década de 1840, hizo paterite, para los dos gobiernos, que el sistema de ocupación compartida no podía continuar durante mucho tiempo sin provocar conflictos entre los colonos estadunidenses e ingleses de la región. El gobierno británico, encabezado por el primer ministro, sir Robert Peel, buscaba insistentemente una solución al problema por medio de un acuerdo basado en el principio del arbitraje, antes de que ocurriera un conflicto armado entre los colonos estadunidenses y británicos de la zona. Aunque en 1845 alrededor de $60 \%$ de los habitantes de la región eran británicos, francocanadienses o metís (mestizos), y si bien casi todos los colonos estadunidenses estaban radi-

${ }^{16}$ Schafer, "British", 1911 , pp. 285-295; Scllers, James K. Polk, 1966, p. 250.

${ }^{17}$ Schuyler, "Polk", 1911, pp. 443-444; Sage, "Orcgon", 1946, pp. 352-355. 


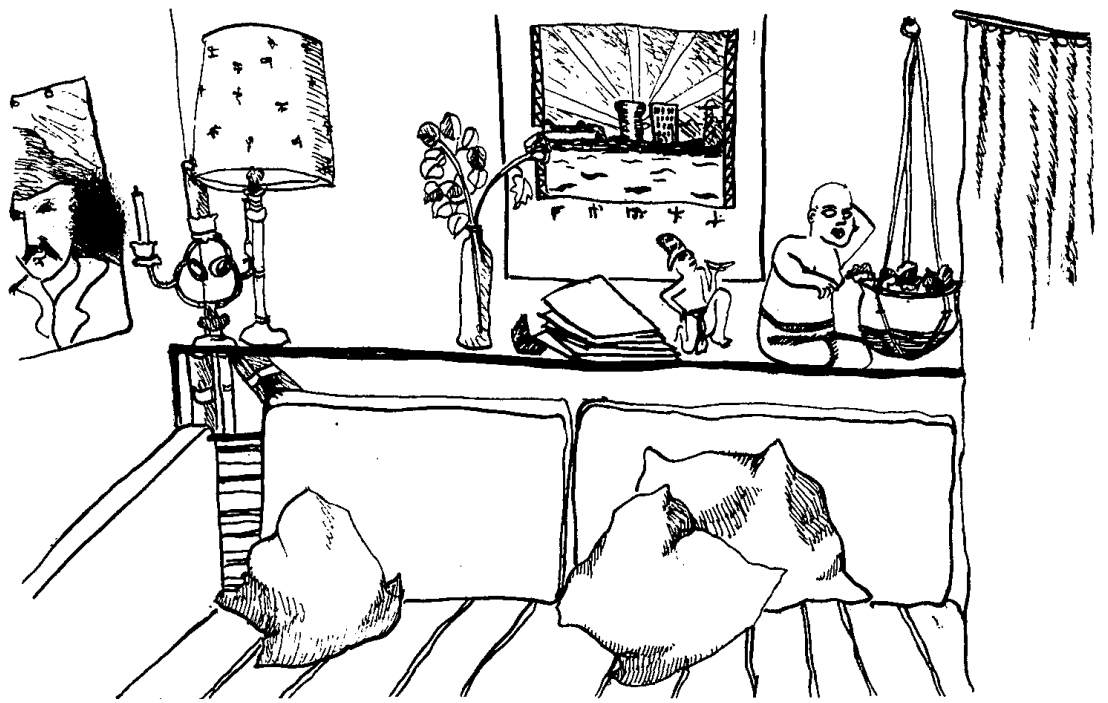

cados en el valle del río Willamette (un tributario del río Columbia que se extendia hacia el sur), un fuerte flujo de inmigrantes de esta nacionalidad llegó a asentarse en la región en el otoño de aquel año. Se tenía la premonición de que, en caso de que se tardara demasiado en llegar a un acuerdo entre lós dos gobiernos, con el tiempo los colonos estadunidenses comenzarían a colonizar en masa la zona norte de Oregon. ${ }^{18}$

${ }^{18}$ Schater, "Orcgon", 1951, pp. 39-16; Sage, "Oregon", 19/6, pp. 355-359; Jones y Vinson, "British", 1953, p. 364; Osburn, "British", 1967. p. 179; Merk, Monroe Doctrine, 1963, p. 69; Preston, Defense, 1977, pp. 12-13. Vétse también la conumicación de James Buchanan, secretario de listado, a louis Mclane, ministro estadunidense en londes, de 26 de febrero de
Los proponentes del "Destino Manifiesto" tenían varios simpatizantes en el Congreso federal, especialmente entre los representantes de las regiones del "oeste" y "noroeste", áreas que correspondian al territorio formado por el medio oeste moderno de Estados Unidos. En 1838, el senador Lewis F. Linn presentó a su Cámara un proyecto de ley que, en caso de que fuera aprobado, permitiría que colonos estadunidenses ocuparan la ribera del río Columbia estableciendo una nueva entidad, ubicada al norte de la latitud $42^{\circ}$ y al oeste de las montañas

1816, Senale Document no. 117, 29\%. Congreso, 1" Sesión (Scric num. 178), pp. 40-44, dorantc los meses más tensos de la clisputa on torno a Oregon. 
Rocallosas, la cual sería denominada "territorio de Oregon". Para ello se debería asignar dinero para el envío de una fuerza expedicionaria de ocupación y para la construcción de un fuerte sobre el río Columbia y de un puerto marítimo en la costa; también se impondría un sistema de impuestos a los colonos. Al año siguiente (1839), el senador Thomas H. Benton presentó al Congreso una petición firmada por los habitantes estadunidenses de Oregon, solicitando al gobierno federal que extendiera sus leyes y su dominio sobre aquella región. La llegada a Oregon, en 1843, de una partida de cerca de 800 inmigrantes estadunidenses encabezados por Peter H. Burnett y Jesse Applegate, ocasionó que el senador Linn presentara otros proyectos de ley ante el Senado defendiendo no sólo el derecho de Estados Unidos a gobernar el territorio, sino proponiendo también la construcción de una línea de fuertes desde los ríos Missouri y Arkansas hasta la desembocadura del río Columbia, y asimismo, como el otorgamiento gratuito de parcelas de terreno a todas aquellas personas que desearan inmigrar a la región. Los proyectos de ley propuestos por Linn ganaron cierto apoyo entre aquellos senadores que simpatizaban con los objetivos de los expansionistas. No obstante que estos proyectos fueron enviados a la Cámara de Representantes para ser sometidos a la consideración de sus miembros, fueron descartados antes de ser sometidos al Senado. ${ }^{19}$

19 Sagc, "Orcgon", 19/6, pp. 355-356 y 358.
Algunos expansionistas de los estados del oeste se aprovecharon del flujo creciente de inmigrantes estadunidenses al territorio para argumentar que tal "tabla de multiplicación" se traduciría a la larga en la conquista pacífica del territorio. La fecundidad estadunidense figuró de manera prominente en todas las discusiones sobre Oregon. Durante la boda del hijo de Francis P. Blair, editor del Congressional Globe, el senador de Carolina del Sur, John C. Calhoun le dijo: "Sr. Blair, ésta es la manera en que conquistaremos Oregon", agregando al mismo tiempo, un comentario que lord Castlereagh había hecho a un negociador estadunidense durante las discusiones en torno a Oregon en una época anterior: "Ustedes no tienen que preocuparse por Oregon; lo conquistarán en sus recámaras". ${ }^{\circ}$ Otros expansionistas estadunidenses expresaron opiniones semejantes. Cuando un político perteneciente al partido de los whigs preguntó a John Quincy Adams si creía que Estados Unidos tenía el derecho de ejercer la soberanía sobre Oregon, Adams lo refirió al verso bíblico que dice: "Sean fructíferos y multipliquense; cultiven la tierra y domínenla". "Ésta -comentó Adams- constituye la base, a mi juicio, no sólo de nuestra soberanía sobre el territorio de Oregon, sino también la referente a la propiedad de los seres humanos en general." Descartó el argumento de que el descubrimien-

20 Debatc sobre Orcgon, Congresstonal Globe, 290. Congreso, $1^{\text {a Sesión, } 10}$ de encro de 1816, p. 180 . Véasc también p. 322 de csta nisma fucnte. 
to y la exploración de las regiones fueran más importantes que la posesión y la utilización de la tierra de acuerdo con la voluntad de Dios. "Defendemos nuestro derecho a dominar aquel país", agregó, "con objeto de que el desierto florezca a la manera de una rosa, para que se establezcan leyes, nazcan hijos y sea subyugada la tierra". Gran Bretaña, afirmó Adams, deseaba Oregon sólo para "mantenerlo abierto a la navegación, para que los cazadores cazaran las fieras salvajes[...], los búfalos, guerreros y salvajes del desierto". ${ }^{21}$

En su discurso inaugural del 4 de marzo de 1845 , el presidente Polk optó por sostener la política formulada por su predecesor en la Casa Blanca, John Tyler, quien en su mensaje anual de diciembre de 1843 había afirmado que Estados Unidos tenía el derecho de soberanía sobre la región entera de Oregon.

Nuestra soberanía sobre la región de Oregon -declaró- es clara e indiscutible y en cstos momentos nuestro pucblo se prepara para consolidar este derecho al ocuparla con sus esposas e hijos. ${ }^{22}$

Inicialmente, Polk no se mostró dispuesto a cooperar con el gobierno británico buscando una solución al problema de Oregon con base en el compromiso, sobre todo en un compromiso que fuera producto del arbi-

21 Congressional Globe, 290. Congreso, $1^{\text {a }}$ Sesión, 9 de febrcro dc 1816, pp. 339-342.

22 Richardson, Compilation, "Inaugural $\mathrm{Ad}$ dress" del presidente Polk, 1907, p. 381. traje. Rechazó esta idea porque consideraba que los derechos territoriales de Estados Unidos no podían ser sometidos al arbitrio de un país extranjero. También dudaba que se pudiera encontrar un árbitro imparcial, además de que cualquier noción de arbitraje implicaría el derecho de Gran Bretaña a una porción del territorio. ${ }^{23}$ Polk tampoco estaba dispuesto a permitir que el poder militar de Gran Bretaña intimara al gobierno estadunidense a aceptar un compromiso. "No debemos permitir que nos disuadan de cualquier política que consideremos justa y apropiada y con la cual Inglaterra no tenga derecho de interferir", confió a George Bancroft, el secretario de la Armada. "Si tenemos que luchar en contra de Gran Bretaña, deberíamos hacerlo ahora, en lugar de dejarlo para nuestros sucesores". ${ }^{21}$

Entre tanto, el primer ministro Peel, influido por el duque de Wellington, había favorecido la adopción de una postura militante que hiciera frente a la política agresiva estadunidense, mostrada por las administraciones de Tyler y Polk, para quedarse con todo el territorio.

I

Yo no tendría miedo a una buena dosis de jactancia preliminar de los estadunidenses - declaró--, la mejor manera de afrontarla scría enviando el Colling-

23 Polk, Diary, 1910, p. 134; Buchanan, Works, 1960, p. 349.

2.1 Tomado del manuscrito inćdito "Biographical Skctch of J. K. Polk", de Gcorge Bancroft, de la Colección Bancroft de la Socicdad Ilistórica de Massachusetts, citado en Sellers, James K. Polk, 1966, p. 2亿价. 
wood [la capitana de la escuadra naval británica en el Pacílico][...] a la descmbocadura del río Columbia. 25

En el transcurso de un debate sobre el tema de Oregon en la Cámara de los Comunes, lord John Russell, el líder del partido whig de la oposición, aseveró:

No puede ser asunto de indiferenciat que un gran territorio, sobre el cual tenemos un derecho de soberanía más justo y evidente, deba ser entregado a raiz de un pronunciamiento jactancioso del presidente de listados Unidos. ${ }^{26}$

En caso de guerra, Canadá no sólo constituiría el principal teatro de combate, sino el botín más grande para la nación ganadora. El papel preponderante de Gran Bretaña en todos los países de América, como potencia extranjera, así como por su prestigio e intereses comerciales a nivel mundial, hizo que su gobierno se sintiera obligado a defender sus colonias norteamericanas. Canadá también tenía cierto valor estratégico para una nación que, como Gran Bretaña, dependia de su armada como fuerza de primera línea defensiva, además de que la ma-

25 Correspondencia intercambiada cntre Abcrdecen y Pecl, 28 de scpticmbic de $18 / 1, \mathrm{cn}$ Clark, "Abcrdecn", 193.3, pp. 237-238. Véasc también la carta de Pecl a $\Lambda$ berdecon, 2 de octubre de 1815, en Clark, IJis/on), 1927. pp. 844815; W. Joncs, Lord Aberdeen, 1958, pp. G6-67; Jones y Vinson, "British", 1953, pp. 358-359; McCabe, "Arbitration", 1960, p. 310.

26 Hansard's Parliamentary Debates, $3 \mathrm{ni}$. seric, vol. 76,1 de abril dc $18 / 5$, columnas 192-193. dera y otros materiales que se producían alli, eran considerados esenciales para el caso de que, por alguna razón, se cortara su suministro desde fuentes ubicadas en el este de Europa. Por añadidura, si bien Canadá podría ser considerado, hasta cierto punto, como un rehén en poder de los estadunidenses para garantizar el "buen comportamiento" del gobierno británico en sus relaciones con ellos, actuaba al mismo tiempo, como una especie de "cabeza de puente" que podría ejercer cierta presión sobre Estados Unidos en el área diplomática y política internacional. También permitiría a los británicos hacer un despliegue más eficaz de sus fuerzas militares en caso de un conflicto armado entre los dos países. ${ }^{27}$

La cuestión principal para los estadunidenses era, en un sentido estratégico, si el territorio canadiense podría ser conquistado antes de la llegada de refuerzos británicos. Después de la guerra de 1812-1814, algunos de sus oficiales habían concluido que su fracaso en aquel conflicto se había debido, en gran parte, a que no habían concentrado la mayor parte de sus fuerzas de ataque en la ribera derecha del río San Lorenzo, para cortar a las poblaciones principales de Montreal y Quebec de su ruta de comunicaciones con Inglaterra. En consecuencia, los estrategas navales estadunidenses se dedicaron a planear su campaña ofensiva y defensiva en la región de los Grandes Lagos, con la idea de colocar a sus fuerzas en una posición de

27 Preston, Defense, 1977, pp. 10-11. 
superioridad durante la etapa inicial de la lucha ${ }^{28}$ Con ese objetivo, en 1843 y $1844,1 \mathrm{a}$ armada estadunidense aumentó su número de barcos de vapor en los Grandes Lagos, el mayor de los cuales era el U.S.S. Michigan, un vapor de ruedas laterales. ${ }^{29}$ En una serie de artículos publicados en el $\mathrm{Na}$ tional Intelligencer, en la primavera de 1845, el teniente Matthew $\mathrm{T}$. Maury, superintendente del Departamento de Cartas e Instrumentos de Navegación en Washington, urgió al Congreso a que aprobara la construcción de un canal que conectaría el sistema fluvial del Mississippi con los Grandes Lagos. También recomendó el establecimiento de un arsenal naval en Chicago y de un astillero en Mackinaw que guardaría el estrecho estratégico entre los lagos Hurón y Michigan; asimismo un muelle para la reparación de barcos, junto con un depósito de carbón y pertrechos de guerra, en Buffalo u otro sitio a orillas del lago Erie. Tales preparativos ayudarían a convencer a los británicos de que no sería conveniente recurrir a las armas como una manera de resolver la disputa en torno a Oregon y, en caso de que se diera la lucha, la mejora en las obras de defensa estadunidenses proporcionaría a sus fuerzas el control de

28 Mackay llitsman, Incredible, 1965, pp. 240-241; Bournc, Brilain, 1967, pp. 332.

29 Correspondencia entre el primer ministro británico, sir Robert Pecl y cl scerctario de las Colonias, lord Stanlcy, en Knaplund, "Armaments", 1935, pp. 473-476; Jones y Vinson, Brilish, 1953, p. 356; Mackay llitsman, Safeguavding, 1968, pp. 144-145 y Preston, Defense, 1977, p. 15. cuatro de los Grandes Lagos (Erie, Hurón, Michigan y Superior). En particular, Maury creía que era esencial, en caso de una guerra, que el ejército estadunidense ocupara inmediatamente la región suroeste del Alto $\mathrm{Ca}$ nadá, la cual, de todos modos, debería constituir, pensaba, parte del territorio estadunidense. ${ }^{30}$ Sin embargo, el Congreso pronto descartó esta propuesta de Maury para la construcción del canal Illinois-Michigan, pues había sospechas, de parte de algunos intereses regionales, sobre todo, el sur de Estados Unidos, de que tal proyecto constituía una estratagema para conseguir fondos federales para el desarrollo del noroeste. ${ }^{31}$

El ejército estadunidense, por su lado, no se encontraba en condiciones adecuadas para enfrentar a las fuerzas armadas de una potencia europea. Desde el final de la guerra de 1812-1814, sus unidades en el noroeste contaban con pocos hombres, y se hallaban dispersas por toda la extensión de la frontera norte en grupos insuficientemente entrenados para emprender operaciones de tipo ofensivo o defensivo. Aunque la milicia contaba con unidades más o menos bien entrenadas en algunos estados, tampoco podía ser utilizada en operaciones ofensivas. La frontera con Canadá estaba también desprovista de

${ }^{30}$ National Intelligencer, 14 y 21 dc marzo, 2 y 15 dc abril y 20 de mayo de $18 / 5$.

${ }^{31}$ Merk, Manifest, 1963, sobre la actitud de los cxpansionistas del sur de Estados Innidos relerente a la anexión de Texas y Oregon, así como con respecto a otras cuestiones, véasc: Hope, "Southern", 1959, pp. 323-338. 
un número suficiente de guarniciones para afrontar una posible invasión británica. Pero su verdadero talón de Aquiles era que, desde su base naval en Halifax, la armada británica podía lanzar asaltos al comercio maritimo y a las ciudades estadunidenses a lo largo de la costa, contra los cuales sus defensores tendrían que luchar con obras de defensa y armamento algo atrasados. 32

El ministro de Guerra británico estaba consciente de los formidables problemas que tenía Canadá en cuanto a necesidades de defensa; también comprendía que, en caso de guerra, tendría que asumir el peso de la mayoría de las operaciones militares con sus propias fuerzas. Estados Unidos ya había sobrepasado a la América del Norte británica en términos de población y de extensión de territorio ocupado. En el transcurso del cuarto de siglo que había seguido a la guerra de 1812-1814, los estadunidenses habían iniciado el desarrollo industrial del valle del río Ohio; asimismo, sus colonos, en número creciente estaban asentándose ya en los territorios de Michigan y Minnesota. En cambio, por lo que se refiere a Canadá, su población estaba concentrada esencialmente en una estrecha franja que se extendia desde Quebec hasta el lago Hurón. La inmigración canadiense, hacia los territorios ubicados al oeste de la región de los Grandes Lagos, no ocurrió hasta el periodo pos-

32 Brucc, Guarding, 1935, pp. 118-132; Bournc, Bvitain, 1967, Pp. 49-52; Preston, Defense, 1977, pp. 17-18 y 20. terior a la Confederación de las colonias en 1867.33

Aunque lord Aberdeen, secretario de Estado para Asuntos Extranjeros de Gran Bretaña, protestó por el aumento de buques de guerra estadunidenses en los Grandes Lagos, aseverando que tal medida constituía una violación del acuerdo de Rush-Bagot de 1817 , no insistió en el asunto debido a que dicho acuerdo no hacía ninguna referencia específica a buques de vapor. ${ }^{31}$ Por tanto, al gobierno británico no le quedaba más alternativa que enviar sus propios refuerzos militares a la región. 35

$\mathrm{Al}$ percatarse de que su insistencia en que el paralelo $54^{\circ} 40^{\prime}$ fuera la frontera en el noroeste no podía ser mantenida sin recurrir a la guerra, el

33 Corcy, Crisis, 1941, pp. 146-157; Staccy, Canacla, 1936, pp. 20-21; Bournc, Brilatin, 1967, pp. 33-52; Mackay Ilitsman, Safeguajaling, 1968, pp. 110-114; Preston, Defense, 1977 , pp. 9-13 y 18-21.

$3 i$ para el texto del intercambio de apuntes entre cl ministro británico sir Charles Bagot y el secretario de Estado Richard Bush, junto con sus documentos anexos, véasc Miller, Treaties, 1931-19/8, pp. 615-654. Hay quc agregar quc, si bicn para este periodo cxistía cl barco de vapor, lats armadas de las nacionces todavía estaban formadas exclusivamente por buques de velia.

35 Durante los años de 1837 a 1814 , el gobicrno británico únicamente había agregaclo un buque de guerra, de tipo convencional -es decir, impulsado por medio de velass- a su lucrza naval quic patrullaba los lagos. Correspondencia intercambiada entre el primer ministro británico, sir Robert Peel, y el secretario de las Colonias, lord Stanley, en Knaplund, "Armaments", 1935, pp. 473-476; Jones y Vinson, "British", 1953, pp. 356 y 358 ; Bournc, Brilain, 1967, pp. 120-169; Mackay IItsman, Safeguarding, 1965, pp. 1141-150. 
gobierno estadunidense ofreció aceptar, el 12 de julio de 1845, el paralelo $49^{\circ}$ como línea de demarcación; al mismo tiempo, permitió que los ingleses usaran los puertos de la parte de la isla de Vancouver situada al sur de dicha línea. Esta oferta fue retirada a finales de agosto al ser rechazada por Richard Pakenham, representante británico en Washington. ${ }^{36}$ El gobierno de Gran Bretaña mantuvo la posición de que el asunto debería ser sometido a arbitraje; no porque creyera que el gobierno estadunidense iba a aceptar esta opción, sino porque iba a proporcionar a los negociadores más tiempo para encontrar una resolución definitiva del problema. Para diciembre de 1846, lord Aberdeen había persuadido a Peel de que el gobierno británico no podía ya mantener su propuesta de que la frontera siguiera el curso del río Columbia. ${ }^{37} \mathrm{~A}$ principios de enero de 1846 y después de que el gobierno estadunidense había rechazado definitivamente la opción de una solución por medio del arbitraje, lord Aberdeen informó a Louis McLane, emba-

36 James Buchanan, el secretario de listado dc listados Unidos, a Richard Pakcnlaam, cl minist ro plenipotenciario inglés en listados Unidos, 12 de julio de 1845; Buchanan a louis Mclanc, cl minist ro estadunidense cn Gran Brctaña, 12 de julio de 18/5; memoránclum de una reunión entre James Buchanan y Richard Pakcnham, 16 de julio de 18/5; Pakenham a Buchanan, 29 de julio de 18/5; todos en Manning, Diplomatic, 1943, pp. 273-288 y 966-975.

37 Abcrdecon a Pakcnham, 3 de dicicmbre de 1845, cn Miller, Treaties, 1931-1948, vol. 5, p. 48; Abcrdecon a Pecl, 28 de dicicmbre de 1845, y Aberdecn a Hudson Ciurncy, 20 de cncro de 1846, cn Clark, Ilistory, 1927, pp. 818-849 y 851. jador estadunidense en Londres, que ya no se pondrían objeciones al recurso de medidas militares de tipo ofensivo o defensivo "basadas en la posibilidad de una guerra con Estados Unidos". 38

A lo largo de 1845 y durante los primeros meses del año siguiente (1846), el gobierno británico se dedicó a aumentar sus defensas en la América del Norte preparándose para una posible guerra. En marzo de 1845, dio órdenes al comandante de la escuadra británica del Pacífico de desplazarse, con las unidades bajo su mando, a la costa de Oregon y de mantenerlas allí en estado de alerta, listas para cualquier emergencia. Durante los meses de verano del mismo año, tanto los ingleses como los estadunidenses enviaron cada vez más naves a esa zona. Los británicos, en particular, comenzaron a efectuar un reconocimiento militar de una región estratégicamente importante entre la sonda de Puget y la desembocadura del río Columbia. Los tenientes Henry J. Warre y Mervin Vavasour, del Cuerpo Real de Ingenieros, fueron enviados a la región con el fin de seleccionar sitios estratégicos para la colocación de cañones que dominaran la entrada al río Columbia

\footnotetext{
38 Carta de sir Robert Pcel a larcina Victoria, 8 de dicientore de 18 i5, en Rives, United S/ales, 1913, vol. 2, pp. 112-113; Aberdecen a liverett, 3 de cncro de 18/6, en Clark, I/is/ory, 1927, p. 849; Mclanc a Buchanan, 3 de concro de 1816, en Congressional Globe, 290. Congreso, $1^{\text {a }}$ Sesión, p. 333; Mclanc a Buchanan, $3 \mathrm{kl}$ lebreroy 3 de marzo de 1846 , en W. Jones, Iow Aberdeen, 1958, p. 78. Véasc también pratl, "Janes K. Polk", 1943, pp. 311-349; Jones y Vinson, "British", 1953, p. $362 ; y$ w. Joncs, Lord Aberdeen, 1958, pp. 80-81.
} 


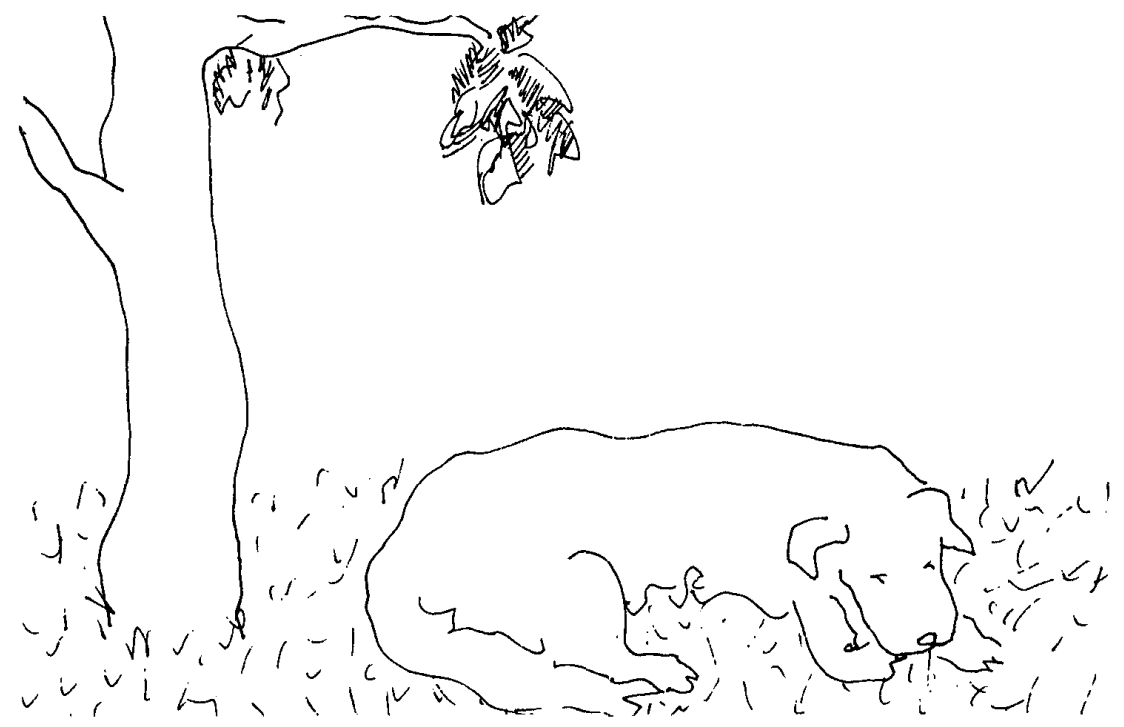

desde el océano. ${ }^{39}$ En una misiva enviada a la Oficina Colonial en Londres, lord Charles Metcalfe, gobernador en jefe de Canadá, aconsejaba de manera imprudente que los estados de la Unión Americana fueran conquistados uno por uno, y que la armada británica procediera a desarticular el comercio maritimo estadunidense, al mismo tiempo que efectuara un bloqueo de los puertos estadunidenses situados a lo largo de la costa del Atlántico y del Golfo de México. Oregon, sugirió Metcalf, podría ser ocupado

39 Referente a las actividacles de Warre $y$ Vavasour, véase la correspondencia intercambiada entre ellos en "Documents", en Oregon, 1909, pp. 1-99; McCabe, "Arbitration", 1960, pp. 313-314; Sellers, James K. Polk, 1966, p. 242; y Galbraith, IJuclson's, 1977, pp. 238-241. por una fuerza militar enviada desde la India. ${ }^{\text {io }}$

Durante los últimos meses de 1845 , la administración Peel autorizó el comienzo de un programa de ampliación del número de naves de la armada, en parte por el deterioro en las relaciones entre Gran Bretaña y Francia, pero también debido a la situación belicosa que estaba produciéndose en la América del Norte. La armada, con aproximadamente 100 naves de línea, era mucho más potente que la de Estados Unidos, y se amplió en un $8 \%$ especialmente respecto a buques de vapor. A principios de febrero, Aberdeen informó a McLane que los preparativos británicos in-

10 McCalbe, "Arbitration", 1960, p. 311. 
cluían la agregación a la armada de "treinta buques de vela, además de naves de vapor y otros barcos de guerra". 11

En enero de 1846, el gobierno de Peel obtuvo la aprobación del Parlamento y la asignación de fondos para la realización de importantes obras militares en Canadá. De esta manera, se ampliaron y mejoraron las defensas de la ciudad Kingston, una de las fortalezas clave para controlar la vía fluvial entre los Grandes Lagos y el río San Lorenzo. También se enviaron unos 200 soldados al fuerte Garry, cuartel general de la Compañía de la Bahía Hudson, situado en el cruce de los ríos Rojo y Assiniboine, que constituía la puerta de entrada al noroeste británico. 42

La situación de las fuerzas armadas estadunidenses era distinta durante esos momentos de crisis. En su mensaje anual al Congreso del 6 de diciembre de 1845, Polk no pidió ningún aumento para la defensa de la nación; de hecho, el presupuesto que solicitó para la armada, correspondiente al año de 1846 , contenía una reducción de una tercera parte respecto a la cantidad solicitada por el presidente Tyler durante el último año de su administración. La llegada de noticias de

41 Buchanan a Mclane, 13 de cliciembre de 1815 y 26 de lebrero de 1816 , en Senate Documenl no. 117, 290. Congreso, $1^{\text {a Sesión (Scries }}$ núms. 173 y 178$)$, pp. $2-4$ y $10-44$; Aberdeen a Pakenham, 3 de febrero de 18 亿, co W. Jones, Lord Aberdeen, 1958, p. 80; Mclanc a Buchanan, 3 de febrero de $18 / 6$, en Miller, Treaties, 1931-1948, pp. 57-5).

42 Mcrk, Moniroe Doctrine, 1963, pp. 101102; Rycrson, Unequal, 1968, pp. 227-228.
Inglaterra referentes a los considerables preparativos militares y navales británicos, motivó a Polk y Bancroft a elaborar, junto con los jefes de los comités congresionales correspondientes, una legislación agregada para la creación de dos regimientos de infantería y la incorporación de la milicia al servicio de la nación o, alternativamente, para el reclutamiento de 50000 voluntarios; y por último, la asignación de 6625000 dólares (un $22 \%$ de los gastos de defensa del año anterior) para el fortalecimiento de la armada, principalmente destinada a la construcción de buques de guerra con cascos de hierro. Todas estas propuestas, sin embargo, acabaron en letra muerta. ${ }^{13}$ En respuesta a la recomendación de febrero de 1846 , del secretario de Estado, James Buchanan, al presidente, de que enviara una petición al Congreso solicitando dinero para la defensa del país, Polk contestó que prefería esperar la llegada de noticias adicionales de Inglaterra. ${ }^{114} \mathrm{Y}$ aunque el secretario de la Armada, George Bancroft, señaló en un informe al gobierno una grave deficiencia respecto a la armada, en cuanto a buques de vapor para alta mar, el presidente declaró que, por el momento no había necesidad de pedir asignaciones adicionales. 15

De esta actitud, el ex presidente John Quincy Adams dedujo que Polk terminaría por aceptar alguna forma

13 Congressional Globe, 2\%o. Congreso, $1^{\text {a }}$ Scsión, 2,12 y 30 de concro de $1846, \mathrm{pp}$. 182 y 257; Sellers, fames K. Polk, 1966 , p. 377.

at Polk, Diary, 1910, vol. 1, pp. 133-134, 257-258, 270, 291-295 y 298-299.

45 Sprout, Rise, 1941, p. 129. 
de arreglo con los británicos. ${ }^{46}$ El 24 de marzo de 1846 , Polk solicitó otra vez al Senado que autorizara un aumento de las fuerzas militares de la nación debido a la creciente crisis en las fronteras norte y sur; pero, al igual que en la ocasión anterior, el Congreso no hizo nada al respecto. ${ }^{47}$ Además, Edward Everett, quien había reemplazado a McLane como representante estadunidense en Londres, aseguró a Aberdeen que los warhawks políticos [halcones de la guerra], estaban en esos momentos en minoría frente a los representantes que deseaban la paz, sobre todo, en el Senado. ${ }^{48}$

Las acciones un tanto dilatorias realizadas por el gobierno estadunidense en lo referente al armamento, se tornan comprensibles considerando que Polk sabía de la propuesta de fijar la frontera en el paralelo $54^{\circ} 40^{\prime}$, irrealizable sin recurrir a la guerra y sin provocar, en consecuencia, un conflicto con Gran Bretaña. Sin embargo, el presidente creía que únicamente la amenaza de una guerra podría obligar a los ingleses a aceptar un acuerdo que fuera igualmente satisfactorio para el gobierno de Estados Unidos. ${ }^{\text {(1) }} \mathrm{A}$ final de cuentas, Polk sometió al Senado un borrador de tratado, basado en 221.

46 Adams, Memoirs, 1814-1877, vol. 12, p.

i7 Polk al Scnado de listados Unidos, $24 \mathrm{dc}$ marzo de 18/6, en Richardson, Compilation, 1907, pp. 126-128; Polk, Diary, 1910, vol. 1, pp. $257,260,270,286.289$.

18 McCabc, "Arhitration", 1960, p. 325.

19 Correspondencia intercambiada contre Buchanan y Mclane, 3 y 26 de febrero de 1816 , Senale Document no. 117, 290. Congreso, 1: Sesión, pp. 31-41. la propuesta que había hecho al gobierno británico en abril de 1845 , con algunas adiciones propuestas por lord Aberdeen, referentes a la inclusión de la porción sureña de la isla de Vancouver como territorio británico, y a derechos de uso del tío Columbia durante un número determinado de años. ${ }^{50}$ $\mathrm{Al}$ proceder de esta manera, Polk no sólo cumplió con una formalidad constitucional (dado que compartía con el Senado las facultades para hacer la guerra y para la elaboración de tratados), sino que usó de esta táctica para poder retroceder de la posición adoptada en su discurso de toma de posesión. Después de su aprobación por la mayoría de votos senatoriales requerida (dos terceras partes), el tratado fue firmado por Buchanan y Packenham a mediados de junio de 1846.51

Gran parte de la desilusión expresada por algunos de los más fervientes expansionistas partidarios del arreglo pacífico del asunto de Oregon pronto

50 Buchanan a Louis Mclanc, $28 \mathrm{dc}$ abril, 6 , 13 y $22 \mathrm{dc}$ junio de $18 / 6$, en Manning, Diplomalic, 1943, pp. 329-330 y 333-335. Relerente a las insercioncs propuestas por los británicos al tratado, véasc Louis Mclane a James Buchaman, 18 de mayo de 1846 , en ibid., pp. 10331010,

St lil tratado oficialmente se conocía como cl Trataclo de Washington ( $\sin$ confundirk, cmpero, con el tratado posterior de cste nombre firmado en 1871), sicndo éste cl lugar en donck sc firmó. Postcriormente, llegó a ser conocido popularmente por otros nombres, tales como cl Tratado de Oregon, el Tratado de Buchanan-Patkcnham, cicćlera. Polk, Diary, 1910, vol. 1, p. 155; Schuyler, "Polk", 1911, pp. 153, 158 y 160-161. El texto completo del tratado se encuentra cn Millor, Treaties, 1931-1918, vol. 5, pp. 3-5. 
se desvaneció con el comienzo de las hostilidades entre Estados Unidos y México, en la segunda semana de mayo de 1846 , que abrió el camino para la extensión del territorio estadunidense hacia el sur, a expensas de un enemigo mucho más débil que Gran Bretaña. Existía cierta prisa en el asunto, debido a que Polk no quería afrontar dos crisis al mismo tiempo, las de ambas fronteras. En parte, México fue la víctima del expansionismo estadunidense debido a que no contaba con el tipo de cobertura militar que los británicos habían erigido en sus colonias norteamericanas. Un senador estadunidense que se oponía a la guerra con México lo expresó de manera burda, "El resto [del continente] será tragado cuando nuestro jugo gástrico requiera otro desayuno caníbal". 52

Entre tanto, en Gran Bretaña, el gobierno de Peel estaba a punto de caer a causa de la abrogación de las llamadas "Corn Laws" (leyes reglamentarias en torno a la comercialización del maíz), que habían proporcionado protección a los productos agrícolas ingleses por medio de aranceles. De hecho, las noticias en torno a la firma del tratado llegaron el mismo día de la caída de la administración Peel. 53

Queda por preguntarse qué tan real fue el peligro de una guerra durante la disputa anglo-estadunidense sobre Oregon. Hay que señalar que existió 231.

52 Citado en Rycrson, Unequal, 1968, p.

53 Polk, Diary, 1910, vol. 1, pp. 381-395; Sage, "Oregon", 1946, pp. 365-366; Scllers, James K. Polk, 1966 , pp. $406-109$. una preocupación considerable, entre mucha gente, por el posible estallido de un conflicto, especialmente durante los primeros meses de 1846; mas debido a la disposición de ambos gobiernos para negociar un arreglo, el peligro fue más aparente que real. Si cualquiera de los dos partidos en pugna no hubiera mostrado la flexibilidad requerida para el mismo, la guerra hubiera constituido la segunda, así como la única alternativa para solucionar el dilema. Como ya se indicó, en tal circunstancia, el verdadero botín de guerra estadunidense constituido por nuevas tierras para la Unión, no hubiera sido sólo la región de Oregon, sino también el noreste del continente, más allá de los límites del Estados Unidos de entonces así como toda la extensión de territorio entre estas dos zonas.

Para los habitantes de las colonias británicas de América del Norte, la amenaza de una invasión extranjera proveniente del sur, de ser anexados voluntariamente o no a Estados Unidos, no finalizó con la resolución violenta de la disputa sobre Oregon. EI sentimiento anexionista estadunidense se mantuvo vivo en las décadas posteriores $^{54} \mathrm{y}$, como consecuencia del deterioro de las relaciones entre Canadá y Estados Unidos durante y después de la guerra de Secesión, debido en parte al sentimiento antibritánico reinante en los estados norteños de la Unión y provocado por las actividades de agentes confederados que operaban desde territorio canadiense durante el conflicto; así como a otros

si Warncr, Idea, 1960), pp. 1-59. 
factores, tales como los ataques lanzados en contra de Canadá en los años 1866,1870 y 1871 por grupos de patriotas irlandeses conocidos como fenianos, surgió otra vez la posibilidad de una guerra entre Estados Unidos y Gran Bretaña. ${ }^{55} \mathrm{El}$ movimiento que culminó en la unión o confederación de cuatro de las colonias británicas de Norteamérica - los Canadás Este y Oeste, Nueva Brunswick y Nueva Escocia- se debió en gran medida a su miedo de ser absorbidas por su poderoso vecino del sur.

En el transcurso de su desarrollo como naciones, Canadá y México compartieron algunas experiencias similares, sobre todo en sus relaciones con Estados Unidos. Para comprender más plenamente el fenómeno del expansionismo estadunidense durante el siglo $\mathrm{XIX}$, es preciso estudiarlo dentro de un contexto mucho más amplio que el que hasta ahora se ha propuesto.

\section{BIBLIOGRAFIA}

-Adams, litrain D., The pouer of idleas in american history, aMs, Press, Nucva York, 1969 (New Haven 1913).

, British inlerest and aclivities in Texas, 1838-1846, Petcr Smith, Gloucester, Mass., 1963.

55 sobre las actividades de los agentes confederados en Canadí, véasc Winks, Canada, 1960, pp. 264-336; Crook, North, 1974, pp. 192-193, 290-291, 345-352 y 357. Relerente a los ataques fenianos y sus repercusiones sobre el desarrollo de Canadí, véase Morton Callahan, American, 1937, pp. 181, 270-294, 299-308, 311-322 y 393; McInnis, Unguarded, 1912, pp. 152-155 y 220-237; Senior, Last, 1991, pp. 37$39,59-98$ y $173-186$.
-Alonzo Cushing, IHarry (comp.), The uriting of Samuel Adams, G. P. Put nam's Sons, Nueva York, 1908.

-Annals of the Congress of the Intled Siales.

-Bancroft, George, "Biografical sketch of J. K. Polk", Collection Bancroft. Sociedad Ilistórica de Massachusetts en Charles Sellers, James K. Polk conlinenlalisl, 1813-1816, Princeton University Press, Princeton, 1966.

-Bourne, Kenneth, Brilain and the balance of power in North America, 1815 1908, University of California Press, Berkcley, 1967.

-Bruce Wesley, Edgar, Guarding the frontier: a siudy offionlier alefense fiom 1815 to 1825 , University of Minnesota Press, Minnesola, 1935.

-Buchanan, James, The works of James buchanan, comprising his speeches, Slate papers and privale correspondence, en John Basset Moorc (comp.), Antiquarian Press, Nucva York, 1960.

-Clark, Robert C., "Aberdeen and Pecl on Oregon, 1844", Oregon IIistorical Quarlerly, vol. 3亿, núm. 3.

, History of the Villamele Va-

lley, Oregon, S. J. Clark, Publishing Company, Chicago, 1927.

-Congresional Cilobe.

-Corcy, Albert B., The crisis of 18.301812 in canadian-american relations, Russcll and Russcll, Nucva York, 1941.

Crook, D. P., The Nosth, the Soulth and the pousers, 1861-1865, John Wilcy and Sons, Nueva York, 1974.

-1) Voto, Bernard, The year of decision: 1816, little, Brown and $C_{\text {.o., Boston, }}$ 1913.

"Documents relatives to Warre and Vavasour's military reconnaisance in ()regon, 1845-1846", Oregon Itislorical Society Quarterly, vol. 10, núm. 1, marzo 1909 , pp. 1-99.

-Francis Adams, Charles (comp.), Memoirs of John Quincy Alams, compri- 
sing portions of his Diary from 1776 to 1848, Lippincott, Filadellia, 1844-1877.

-Galbraith, John S., The IIudson's Bay Company as an imperial factor, 1821 1869, Octagon Books, Nucva York, 1977.

-Hacker, Louis M. (comp.), The shaping of the american tradilion, Columbia University Press, Nucva York, 19'17.

-Hictala, Thomas R., Manifest design: anxious agrandizement in late jacksonian America, Cornell University Press, Ithaca, 1985.

-Hope, Franklin, John, "The southern expansionists of 1816", "The foumal of Soulhern IIislory, vol. 25, núm. 3, agosto 1959.

- Horsman, Reginald, Race and Manifest Destiny: the origins of american racial anglosaxonism, Harvard University Press, Cambridge, 1981.

Jackson, Shcldon G., "Two pro-british plots in Alta California", Southern California Quarterly, vol. 55, núm. 2, verano, 1973.

Jones, Howard, To the Webster-Ashburton Trealy: a story in anglo-american relations, 178.3-1813, University of North Carolina Press, Chapel Hill, 1977.

-Jones, Wilbur D., Lord Aberdeen and the Americas, University of (icorgia Press, Athens, 1958.

-Jones, Wilbur D. y Charles Vinson, "British preparedness and the ()regon settlement", Pacific IIistorical Review, vol. 2, núm. 1, noviembre 1953.

-Kerr, W. B., "The american invation of Nova Scotia", Canadian Defense Quartevly, vol. 13, núm. 4, julio 1936.

-Knaplund, Paul, "The armament in the Great Lakes, 1814", American Iistovical Revieu', vol. 40, núm. 3, abril 1935.

-Mackay Jlitsman, J., The incredible war of 1812: a military history, Iniversity of Toronto Press, Toronto, 1965.

- Safeguarding Canada, 1763-1871, University of 'l'oronto, 'Toronto, 1968 .
-McCabc, James O., "Arbitration and the Oregon question", Canadian IIislorical Revieu, vol. 11, 1960.

-Manning, William R., Diplomatic correspondence of the United Stales: canadian relations, $1784-1860$, Carncgic lindow ment of International Peace, Washington, 1913.

-Mc Innins, Edgar W., The unguarded fronlier: a hislory of american-canadian relations, Double Day/Doran and Co., Garden City, 1912.

-Mcrck, Frederick, Manifest Desliny and mission in american history: a reinlerpretalion, Vintagc Books, Nucva York, 1963

, The Monroe Doctrine and american expansionism, 1813-1819, $\mathrm{Al}$ fred $\Lambda$. Knopl, Nueva York, 1966.

-Miller, Junter, (comp.), Trealies and other international Acts of the Uniled Slates of America, Government printing Office, Washington, 1931-1918.

-Morton Callahan, Jamcs, American foreing policy in canadian relations, Mcmillan, Nueva York, 1937.

-National Inteligencer.

-New York Ilerald.

-New York Morning News.

-Osburn Winther, Oscar, "The british in Oregon country: a triptych view", lacifï Northuest Quarlerly, vol. 8, núm. 亿, octubre 1967.

O'Sullivan, John l., "Annexalion", Democralic Review, 17 julio 18/15.

-Paullin, Charles O., "Ihe carly choice of the forty-ninth parallel as a boundary line", The Canadian IIs/orical Revieu, vol. 1, núm. 1, marso 1923.

-Polk, James K., The diayy of James $K$. Polk during his presidency, 1815 to 1849, en Milo Milton Quaili (comp.), $\Lambda$. C. Mc Clury and Co., Chicago, 1910.

-Porter Shortridge, Wilson, "Ilhe canadian amcrican fronteir during the rebellion of 1837-1838", Canadian Ilistorical Review, vol. 7, núm. 1, marło 1926. 
-Pratt, Julius W., Expansionists of 1812, Peter Smith, Gloucester, Mass., 1957.

"John L. O'Sullivan and Manifest Destiny", New York History, vol. 14, núm. 3, julio 1933 .

- "The origin of Manifest Destiny", American Historical Review, vol. 32, núm. 4, julio 1927.

-Preston, Richard A., The defense of the undefended border: planning for war in Nolh America, 1867-1939, Mc Gill/ Qucens's Iniversity Press, Montreal y Londres, 1977.

-Richardson, Janes D. (comp.), A compilation of the messages and papers of the presidents, 1789-1902, Burcau of National Literature and Art, Washington, 1907.

-Rives, G. L., The Uniled States and Mexico, 1821-1818, s.e., Nucva York, 1913.

-Rycrson, Stanley B., Unequal union: Confederation and the roule of conflict in Canadas, 1815-1873, International Publishers, Nueva York, 1968.

-Sage, Walter N., "The Oregon 'Treaty of 1846", Canadian Historical Review, vol. 27, núm. 4, diciembre 1946.

-Schaler, Joseph, "The british atticude toward the Orcgon question", American IIistorical Revieu, vol. 16, núm. 2, cncro 1911.

, "Orcgon pioncers and amehistory dedicaled to Frederick Jackson Turner, Pcter Smith, Nueva York, 1951 (Henry Holt and Co., 1910).
-Schuyler, R. L., "Polk and the Oregon compromise of 1846", Political Sctence Quarterly, vol. 26, núm. 3, septicmbre 1911.

-Sellers, Charles, James K. Polk, conttnentalist, 1813-1846, Princeton University Press, Princeton, 1966.

-Senior, Hereward, The last invalion of Canada: the fenian raids, 1866-1870, Dundern Press, Toronto, 1991.

-Smith, Justin H., Our struggle for the fourleenth colony: Canada and the american revolution, G. P. Putnam's Sons, Nueva York, 1907, 2 vols.

-Sprout, Margaret, The rise of american naval power, 1776-1918, University of Princeton Press, Princeton, 1914.

-Stacey, Charles P., Canada and the brilish army, Longmans/Green and Co., Londres, 1936.

-Weinberg, Albert R., Manifest Destiny: a study of nationalist expansionism in american history, Quadrangle Books, Chicago, 1963.

-Warner, Donald F., The idea of continental union: agitation for the annexation of Canada to the Uniled States, 1849-1893, University of Kentucky l'ress, s.1., 1960 .

-W cinberg, Albert K., Manifest Destiny: a study of nationaltst expansionism in american history, Quadrangle Books, Chicago, 1963.

-Winks, Robin W., Canada and the Uniled States: the civil war years, the Jonhs Iopkins Press, Baltimore, 1960. 